\title{
AGO Recommendations for the Diagnosis and Therapy of Breast Cancer
}

\author{
Christoph Thomssen on behalf of the Arbeitsgemeinschaft für Gynäkologische Onkologie (AGO), \\ 'AGO Kommission Mamma'*
}

Department of Gynecology, Martin-Luther-University Halle-Wittenberg, Germany

*Co-Authors (members of the 'AGO Kommission Mamma'): Dr. Ingo Bauerfeind, München; Dr. Joachim Bischoff, Magdeburg; Prof. Dr. Jens Uwe Blohmer, Berlin; Dr. Klaus Brunnert, Osnabrück; Prof. Dr. Dr. Serban D. Costa, Magdeburg; Prof. Dr. Peter Dall, Lüneburg; Prof. Dr. Ingo J. Diel, Mannheim ; PD Dr. Nikos Fersis, Heidelberg; Prof. Dr. Michael Friedrich, Lübeck; PD Dr. Kay Friedrichs, Hamburg; Prof. Dr. Bernd Gerber, Rostock; Prof. Dr. Uwe-Jochen Göhring, Bonn; Prof. Dr. Volker Hanf, Fürth; Prof. Dr. Nadia Harbeck, München; Prof. Dr. Jens Huober, Tübingen; Prof. Dr. Christian Jackisch, Offenbach; Prof. Dr. Wolfgang Janni, München; Prof. Dr. Walter Jonat, Kiel (DKH); Prof. Dr. Manfred Kaufmann, Frankfurt; Prof. Dr. Hans-Joachim Lück, Wiesbaden; Prof. Dr. Nicolai Maass, Kiel; Prof. Dr. Volker Möbus, Frankfurt; Prof. Dr. Ulrike Nitz, Düsseldorf ; PD Dr. Carsten Oberhoff, Essen; Dr. Mahdi Rezai, Düsseldorf; Prof. Dr. Gerhard Schaller, Berlin; Prof. Dr. Anton Scharl, Amberg; Prof. Dr. Rita Schmutzler, Köln; Prof. Dr. Andreas Schneeweiß, Heidelberg (AIO); Prof. Dr. Ingrid Schreer, Kiel (DGS); Prof. Dr. H. Kreipe (DGP); Prof. Dr. Peter Sinn, Heidelberg (Pathologie); Prof. Dr. Erich F. Solomayer, Tübingen; PD Dr. Rainer Souchon, Hagen (ARO); Prof. Dr. Elmar Stickeler, Freiburg; Prof. Dr. Christoph Thomssen, Halle (Chairman of the 'AGO Kommission Mamma'); Prof. Dr. Michael Untch, Berlin; Prof. Dr. Gunter von Minckwitz, Neu-Isenburg / Frankfurt.

\section{Key Words}

Breast cancer - Guidelines - Treatment recommendation . AGO Breast Commission · Evidence based

\section{Summary}

In January 2007, the 'AGO Kommission Mamma' for the 5th time updated the 'AGO Recommendations for the Diagnostic and Therapy of Breast Cancer' that were established and published for the first time in 2002. The most important statements and modifications are described here. With regard to adjuvant therapy, the definition of the recommended regimens could be established more precisely. The increasing knowledge about the clinical value of sentinel lymph node excision is taken into consideration. For the pathological work-up, the needs and standards of additional markers and prognostic factors were better defined and adjusted to the guidelines of the German pathologists. The routine use of gene arrays for therapy decision is still rejected. Detailed recommendations were established for acute and long-term side effects of therapy. In the chapter 'specific situations', CUP (carcinoma of unknown primary) syndrome and phyllodes tumor were included. Taking into account the improved prognosis of breast cancer, specific advice for survivors and information about complementary therapy, hormone therapies, and contraception was prepared in detail. The treatment principles of metastastic disease have not changed substantially, thus pronouncing the significance of guiding therapy by defining the goal and estimating the therapeutic index for each situation.
Schlüsselwörter

Mammakarzinom · Leitlinien · Therapieempfehlung .

AGO Kommission Mamma · Evidenzbasiert

\section{Zusammenfassung}

Im Januar 2007 hat die AGO-Kommission Mamma zum fünften Mal ihre 2002 zum ersten Mal vorgestellten "AGO Empfehlungen zur Diagnostik und Therapie des Mammakarzinoms" auf den neuesten Stand gebracht. Die wichtigsten Empfehlungen und Veränderungen werden im Folgenden dargestellt. Hinsichtlich der adjuvanten systemischen Therapie wurden die empfohlenen Schemata explizit und detailliert dargestellt. Die zunehmenden Erfahrungen mit der Wächterlymphknoten-Exzision werden ausführlich berücksichtigt. Für die histopathologische Aufarbeitung werden die Standards der zusätzlichen Marker und Prognosefaktoren besser definiert und an die Leitlinien der deutschen Pathologen angepasst. Die Anwendung von Genexpressionsprofilen für die Therapieentscheidung in der Routine kann nicht empfohlen werden. Eine detaillierte Darstellung beschäftigt sich mit den Akut- und Langzeitnebenwirkungen der Therapie. Im Kapitel "Besondere Situationen" werden auch das CUP (carcinoma of unknown primary)Syndrom und der Phylloidestumor behandelt. In Anbetracht einer zunehmend besseren Prognose bei Brustkrebs, wurden spezifische Ratschläge für Überlebende («survivors») erarbeitet, auch Informationen über Komplementärtherapien, Hormontherapie und Kontrazeption werden im Detail dargestellt. Die Behandlungsprinzipien beim metastasierten Mammakarzinom haben sich nicht wesentlich verändert. Unverändert gilt, dass das Ziel Therapie jeweils definiert sein muss und die Therapie an die jeweilige Situation unter Einbeziehung des therapeutischen Index angepasst werden muss.

\begin{tabular}{ll}
\hline KARGER & @ 2007 S. Karger GmbH, Freiburg \\
Fax +4976145207 14 & Accessible online at: \\
$\begin{array}{l}\text { E-mail Information@Karger.de } \\
\text { www.karger.com }\end{array}$ & www.karger.com/brc
\end{tabular}




\section{Introduction}

The Breast Group of the Arbeitsgemeinschaft Gynäkologische Onkologie ('AGO Kommission Mamma') has edited the yearly updated guidelines for the diagnosis and therapy of breast cancer. The current edition is the 5 th update since the first edition in 2002. Our intention was always to generate recommendations on the basis of the current evidence of published data. In order to facilitate the use of these guidelines, we added an AGO Recommendation Score to each statement that demonstrates the majority opinion of the members of the commission (table 1).

In Germany, the AGO recommendations are widely spread and used. They can be downloaded from the AGO website both in English and in German (www.ago-online.de). The recommendations have contributed substantially to the standardization of the breast cancer treatment in Germany, as it has been demonstrated by repeated inquiries [1]. The generation process of the AGO recommendations also provides the basis for the interdisciplinary so-called $\mathrm{S} 3$ guideline of the German Cancer Society (DKG e.V.; http://krebsgesellschaft.de/wub_llevidenzbasiert_mammakarzinom.html) that has recently been updated 3 years after the 1st edition. The enormous work load of an interdisciplinary discussion with the result of a methodologically high-level guideline cannot be provided annually. The AGO guidelines fill this gap perfectly by providing revised and evidence-based recommendations every year. In contrast, the recommendations of St. Gallen explicitly do not intend to be evidence-based. Rather, these recommendations represent the opinion of the international expert panel of St Gallen and were designed to confirm the minimal standard that can be fulfilled in most countries of the world. It is the task of the AGO recommendations and the S3 guideline of the German Cancer Society to translate the international St Gallen recommendations into guidelines that are focused on the special German national situation. In this report, the most important statements and innovations of the current update are presented.

\section{Methodology}

The AGO recommendations were established in 2002. Even then, we established a methodology by which literature should be screened and integrated into our guidelines [2]. Each subject or chapter had to be set up by 1 or 2 members of the guideline group and then presented, discussed, and voted on in the plenary group. The literature search for best evidence for each statement is one way to guarantee the independence of the content of the guideline. On the other hand, as a specialist in his or her particular field, each member of the guideline group has contact to the industry through research cooperation and funding, advisory boards, presentations, and other activities. Obviously, the active members of the commission cannot be asked to leave such co-operations in order to participate in the creation of the guideline. Therefore, an 'opinion-forming' interest cannot a priori be excluded. In order to minimize that problem, the following mechanisms were implemented: i) Different authors are chosen for the yearly update of each chapter; ii) Each statement is discussed by all members, and the vote of a significant majority is required for acceptance; iii) Every author must declare potential conflicts of interest as a basis for being allowed to participate in the preparation and voting process.

\section{The Guideline Statements}

\section{Screening, Risk Groups, Prevention}

Mammography is still the standard in screening for breast cancer. For women aged between 50 and 70, we recommend a mammography every 2 years. In younger women (40-50 years), mammography should even be performed at shorter intervals (every 12 or 18 months). Ultrasound and magnetic resonance imaging (MRI) are valuable additional methods but should not be applied as a single screening method. In the discussion and counseling concerning screening and prophylaxis of hereditary breast cancer, it should be emphasized that the subject of interest are healthy women. Before any sort of intervention is implemented, risks and benefits must be estimated thoroughly and weighed up against each other in each individual case. Nowadays, counseling can be performed on the basis of rather reliable data. A clear catalogue of indications for tumor-genetic counseling has been set up. In the case of a proven BRCA-1/-2 mutation, bilateral oophorectomy is recommended after the age of 39 years if family planning has been completed.
Table 1. AGO grades of recommendation (from: 'AGO

Kommission

Mamma', guidelines 2007 version 1.1 ; www.ago-online.de)
++ This investigation or therapeutic intervention is highly beneficial for patients, can be recommended without restriction, and should be performed.

$+\quad$ This investigation or therapeutic intervention is of limited benefit for patients and can be performed.

+/- This investigation or therapeutic intervention has not shown benefit for patients and may be performed only in individual cases. According to current knowledge a general recommendation cannot be given.

- This investigation or therapeutic intervention can be of disadvantage for patients and might not be performed.

- - This investigation or therapeutic intervention is of clear disadvantage for patients and should be avoided or omitted in any case. 
Table 2. Sentinel lymph node excision: list of indications (from: 'AGO Kommission Mamma’, guidelines 2007 version 1.1; www.ago-online.de)

\begin{tabular}{lll}
\hline Indication & LoE / GR & AGO $^{\mathrm{a}}$ \\
\hline Clinically (cN0) / sonographically negative axilla & 1b A & ++ \\
T1 & 1b A & ++ \\
T2 & $2 \mathrm{~b} \mathrm{~B}$ & + \\
DCIS $\geq 5 \mathrm{~cm}$ or if mastectomy is required & $3 \mathrm{~b} \mathrm{~B}$ & + \\
Multifocal lesions & 2b B & + \\
Before primary chemotherapy & $3 \mathrm{~b} \mathrm{C}$ & $+^{\mathrm{b}}$ \\
After primary systemic therapy & 2b B & $+/-^{\mathrm{b}}$ \\
\hline
\end{tabular}

${ }^{\mathrm{a}} \mathrm{AGO}$ grades of recommendation.

bStudy participation recommended.

LoE / GR = Level of evidence (according Oxford Centre for Evidence-

Based Medicine Levels of Evidence) and grades of recommendation

(May 2001; www.cebm.net/levels_of_evidence.asp.);

DCIS $=$ ductal carcinoma in situ.

\section{Precursor Lesions, DCIS}

Non-palpable suspicious lesions (microcalcifications, disrupted of architecture) should be brought to histological diagnosis by mammography-guided stereotactic needle biopsies (core-needle biopsy, high-speed needle biopsy, or vacuum-assisted needle biopsy). Only with a histological diagnosis, patients can be counseled in a proper way, and the further procedure can be planned. In many cases, an open biopsy (under general anesthesia) can be avoided. Histologically proven precursor lesions (ADH, DCIS, LN/LIN) have to be further confirmed by an open biopsy, which in the case of non-palpable lesions has to also be wire-guided, since $20-30 \%$ of non-invasive or even invasive breast cancer is found behind such lesions. The only exception is a diagnosis of LIN 1 (ALH) as an incidental finding (without mammographic correlation) [3, 4]. In the 2007 update, an entire chapter has been dedicated to ductal carcinoma in situ (DCIS). The requirements for the operation - wide excision with adequate lesion-free margins - are still valid. The important value of the postoperative radiotherapy of the involved breast has been confirmed by recently published data [5]: a relative risk reduction of in-breast recurrences can be achieved by postoperative breast irradiation independent of the size of the lesion, grading, and extent of resection. On the other hand, no benefit with regard to overall survival has been demonstrated yet. Therefore, advantages and disadvantages must still be balanced and discussed with each single patient.

\section{Diagnostic Assessment - Histopathology, Prognostic, and Predictive Factors}

The diagnostic assessment of suspicious lesions should preferably be performed by core needle, high speed or vacuum assisted biopsy, in most cases guided by appropriate imaging. An open biopsy for diagnostic assessment may have disadvan- tages with regard to patient counseling and therapy planning. There are reasonable arguments in favor of general preoperative MRI of the breasts (e.g. for exact topographic orientation of the lesion, or for the detection of further cancerous foci), however, it cannot be generally recommended since data from randomized trials do not exist. General consensus could be obtained only in lobular carcinoma aiming at better detection of further lesions. Baseline staging by imaging at the time of first presentation - liver ultrasound, chest X-ray, bone scan - for the detection of distant metastases is recommended only in cases of high-risk breast cancer or in symptomatic patients. Particularly in patients with T1N0 cancer, no benefit of routine imaging has been observed, and routine imaging is not recommended any more. The description of the cancer should comprise the histological type and the following prognostic and predictive factors: grading, vessel invasion, steroid hormone receptors (estrogen receptor, progesterone receptor), and HER2 expression. The determination of the well validated invasion factors UPA and PAI-1 may assist in the evaluation of risk assessment in node-negative breast cancer (LoE 1a AGO+). According to recent data on gene expression profiles, basal cell-like and triple-negative cancers, respectively, seem to have a particularly unfavorable prognosis. However, currently available gene, methylation, and protein profiles are not ready for routine use so far. Overexpression of topoisomerase- $2 \alpha$ should not be used for treatment decisions. The putative predictive impact, originally discussed, has not been confirmed with prolonged follow-up of the BCIRG-006-trial [6]. It is also still unproven whether the status or the level of expression of steroid hormone receptors is useful for decisions on adjuvant chemotherapy.

\section{Surgery, Sentinel Lymph Node Excision, Axillary Dissection} In most breast cancers, breast conserving therapy is acknowledged as the standard therapy. Only in the case of multricentric or inflammatory lesions or if complete excision cannot be achieved, mastectomy should be performed. The most important modifications are related to the indication of axillary dissection and sentinel lymph node excision (SLNE). Axillary treatment should be restricted to SLNE in $\mathrm{T} 1$ and T2 lesions if clinical and sonographic examination does not demonstrate any suspicion of lymph node metastasis. In multifocal carcinoma and in huge DCIS lesions $(\geq 5$ $\mathrm{cm}$ in diameter), SLNE can be considered. SLNE can be helpful prior to primary systemic therapy. Recent data suggest that SLNE may be adequate even in multicentric cancers, after prior tumor excision, and in male breast cancer (table 2). Axillary dissection should be performed in cases of tumor infiltration of the sentinel node, after extensive prior surgery of the breast or axilla, after primary systemic (neoadjuvant) therapy, and in inflammatory breast cancer. Axillary dissection must not be performed in less extensive DCIS ( $\leq 5 \mathrm{~cm}$ in diameter). SLNE should also be avoided in patients at low risk of lymph node metastasis: tumor diame- 
ter of $<1 \mathrm{~mm}$ or otherwise favorable biology (e.g. elderly with highly differentiated (G1), steroid hormone receptorpositive $\mathrm{T} 1 \mathrm{cN} 0$ tumors).

\section{Adjuvant Systemic Therapy}

Breast cancer is still considered as a primary systemic disease. Disseminated tumor cells can be detected in more than $30 \%$ of patients by using appropriate techniques [7, 8]. Adjuvant systemic treatment is aimed at reducing the number of disseminated cells in order to prevent the growth of distant recurrences later in the follow-up. In most patients, state of the art adjuvant systemic treatment consists of the combination of chemotherapy and endocrine therapy. The EBCTCG overview [9] demonstrated a reduction in the cumulative risk of death after 15 years of observation of as much as $57 \%$ by using tamoxifen-and anthracycline-containing regimen. In HER2-overexpressing tumors, an additional substantial reduction in the risk of death can be expected $[10,11]$

\section{Adjuvant Endocrine Therapy in Premenopausal Patients}

In steroid hormone receptor-positive patients, adjuvant systemic standard therapy is the sequential combination of chemotherapy and endocrine therapy. In premenopausal patients, tamoxifen has to be prescribed for 5 years, beginning immediately after completing adjuvant chemotherapy. Treatment with aromatase inhibitors only is contraindicated in premenopausal patients, since it would potentially lead to ovarian stimulation with rising estrogen levels. In patients who experienced chemotherapy-induced amenorrhea, aromatase inhibitors should not be prescribed without monitoring the endocrine situation thoroughly. Remaining or regaining ovarian function is possible even without observing menstruation. At the very least, the endocrine situation should be monitored in short intervals, and the postmenopausal status must be documented by measuring follicle stimulating hormone (FSH) and E2 serum levels. In some patients, ovarian suppression with gonadotropin-releasing hormone $(\mathrm{GnRH})$ analogues for 2 years in combination with tamoxifen for 5 years may be as effective as adjuvant chemotherapy with subsequent tamoxifen. However, it is still unclear which group of patients this therapy can be recommended to. In G1 patients, tamoxifen might be sufficient, in many $\mathrm{G} 2$ patients, adjuvant chemotherapy might be indicated. The 'AGO Kommission Mamma' does not generally recommend ovarian suppression after adjuvant chemotherapy. These patients should preferably be treated within prospective clinical trials (e.g. SOFT trial). Based on the current knowledge, ovarian suppression for 2 years should be considered only in very young patients ( $<40$ years of age).

\section{Adjuvant Endocrine Therapy in Postmenopausal Patients}

Tamoxifen treatment for 5 years is considered state of the art. The use of aromatase inhibitors is also well accepted, and is highly recommended by the 'AGO Kommission Mamma'. However, it is still unsolved whether postmenopausal patients should be treated exclusively and upfront with aromatase inhibitors or only after pre-treatment with tamoxifen for 2 years. There is an agreement that node-positive patients should receive aromatase inhibitors after 5 years of tamoxifen for an additional 3-5 years.

\section{Adjuvant Chemotherapy and Antibody Therapy}

Anthracycline combinations are still considered as standard of adjuvant chemotherapy. In node-positive disease, taxanes should be included, and dose-dense regimens seem to be beneficial for theses patients. Treatment within clinical trials is recommended. Numerous chemotherapy combinations were individually evaluated and presented hierarchically. With regard to anthracycline-containing regimens, the 'AGO Kommission Mamma' still recommends French FEC (5-fluorouracil, epirubicin, cyclophosphamide; $\left.\mathrm{FE}_{100} \mathrm{C}^{*} 6 \mathrm{q} 3 \mathrm{w}\right)$ as the best compromise between probable efficacy and potential side effects. Concerning taxane-containing combinations, sequential FEC-docetaxel $\left(\mathrm{FE}_{100} \mathrm{C} * 3 \mathrm{q} 3 \mathrm{w}\right.$ followed by docetax$\mathrm{el}_{100} * 3 \mathrm{q} 3 \mathrm{w}$ ), well known from French studies (PACS-01), and the BCIRG combination docetaxel-doxorubicin/cyclophosphamide ('DAC' or 'TAC') are preferred. Adjuvant treatment with trastuzumab for 1 year is indicated for tumors with HER2 overexpression (node-positive and high-risk nodenegative).

\section{Primary Systemic Therapy (Neo-Adjuvant Therapy)}

The indications for primary systemic (neo-adjuvant) chemotherapy are valid without modification. Based on extensive experiences with neo-adjuvant chemotherapies that were particularly established within German studies, distinct chemotherapy regimens are recommended. Naturally, the expected effect of a neo-adjuvant regimen should not be inferior to the standard adjuvant therapy in similar indications. From own experience, the first author (CT) considers the paclitaxelFAC/FEC sequence as it was published by Green et al. [12] to be an effective regimen as well. Observing remission by neoadjuvant therapy, it seems to be feasible to perform tumor excision within the new margins, as long as the resection margins are free from tumor infiltration. From a technical point of view, SLNE can be performed prior or after primary systemic therapy. However, the clinical value of either procedure is still unclear, so that this procedure should be performed only within clinical trials (e.g. SENTINA trial). SLNE only after neo-adjuvant chemotherapy may not be an adequate axillary treatment.

\section{Radiotherapy}

The radiotherapy recommendations were not changed substantially, but consolidated based on improved current data. Postmastectomy radiotherapy (PMRT) is standard of care in patients with T3 and T4 tumors, and if 3 or more lymph nodes are tumor infiltrated. In the case of less lymph node involvement (1-3 axillary lymph nodes), PMRT may be advantageous particularly in young patients. The indication in pa- 
Table 3. Complementary therapy: nutrition after breast cancer diagnosis (from 'AGO Kommission Mamma', guidelines 2007 version 1.1; www.ago-online.de)

\begin{tabular}{lll}
\hline Recommendation & LoE / GR & AGO \\
\hline Adherence to normal BMI (improves prognosis - DFS/OS) & $2 \mathrm{~b} \mathrm{~B}$ & ++ \\
Low fat diet (improves prognosis/DFS especially in & & \\
postmenopausal, ER-negative patients; $\leq 20 \%$ fat calories, & & \\
$\quad$ only with dietary counseling!) & $1 \mathrm{~b} \mathrm{~B}$ & + \\
Fruit and vegetables & $3 \mathrm{a} \mathrm{B}$ & $+/-$ \\
Whole grain & $4 \mathrm{C}$ & $+/-$ \\
Dietary extremes (are associated with less favorable outcomes) & $1 \mathrm{~b} \mathrm{~B}$ & -- \\
Alcohol consumption (even minimal alcohol consumption & & \\
$\quad$ increases breast cancer risk after diagnosis and should be avoided) & $4 \mathrm{C}$ & - \\
\hline
\end{tabular}

LoE $/ \mathrm{GR}=$ Level of Evidence and grades of recommendation (see above); BMI = body mass index; DFS = disease-free survival: OS = overall survival; ER = estrogen receptor. tients who underwent primary systemic treatment should be guided by the pre-therapeutic situation. For patients with extensive lymph node involvement, the 'AGO Kommission Mamma' recommends also to irradiate the supraclavicular lymph node region. Intraoperative and postoperative partial breast irradiation is still considered experimental. Particularly in young women $(<50$ years), boost irradiation of the tumor bed subsequent to the whole breast irradiation (with $50 \mathrm{~Gy}$ ) is accepted as beneficial.

\section{Complementary Therapy, Hormone Replacement Therapy, and Survivorship}

The current recommendations in detail describe the different options of supportive measures that moderate potential therapy side effects. Recommendations were also established for living with the diagnosis of breast cancer. With regard to daily live, evidence has accumulated that normalization of body weight and physical exercise, such as the equivalent of 3-5 h of walking per week, can help improve quality of life, fatigue, and perhaps even prognosis. According to a large trial, a 'low-fat diet' is able to reduce the recurrence rate of breast cancer, interestingly mainly in steroid hormone receptor-negative breast cancer patients. In contrast, the AGO does not recommend the use of special diets, and other modes of additional nutritional measures (orthomolecular elements such as selenium, zinc etc., high-dose vitamins, proteolytic enzymes such as papain, trypsin, chymotrypsin, soy-derived products such as phytoestrogens, mistletoe extracts, thymus, spleen peptides, oxygene and ozone therapy), since also unfavorable effects might occur (table 3). Taking into account the potential risks of hormone replacement with regard to breast cancer promotion, and the proven benefits of treatment with antiestrogens, endocrine therapies with gonadal steroids are considered to be problematic. Particularly patients with hormone receptorpositive tumors should be advised not to use systemic estrogen therapy. The rejection of hormone use is extended also to oral contraception. Non-hormonal contraceptives can be used without any objections. No clear recommendations can be given with regard to levonorgestrel-delivering intrauterine devices. Since there are no prospective studies with regard to contraception after breast cancer, all these recommendations are based on indirect conclusions only.

\section{Follow-Up Surveillance of Breast Cancer Patients}

Evidence for the lack of benefit of scheduled imaging-supported surveillance after primary therapy of breast cancer was obtained during a time when treatment of metastases was rather simple. However, it is still unproven that intensified follow-up has any impact on overall survival or quality of life. Concordant with the international guidelines, the current AGO recommendations also advise against surveillance by imaging including positron emission tomography (PET) for screening or detection of metastases. For follow-up of breast cancer patients, we recommend to speak intensively with each patient about complaints in the interval since the last visit, to thoroughly perform clinical examination, and to prescribe mammography of the affected breast every 6 months (contralateral 12 months) in order to detect potential curable locoregional recurrences or secondary cancers. In summary, with regard to follow-up, the current recommendations correspond to those of 2006.

\section{Locoregional Recurrence}

Locoregional recurrences can potentially be cured by surgery and/or radiotherapy. In cases of in-breast recurrences with a clinically negative axilla, a secondary axillary intervention (sentinel lymph node excision, axillary dissection) is not indicated. Currently, no data from randomized trials are available as to whether or not breast conserving surgery can be performed for treatment of in-breast recurrences. For locoregional recurrences after mastectomy, resection with tumorfree margins (R0) should be tried, and irradiation of the affected breast wall is indicated if no prior radiotherapy has been performed. With regard to systemic therapy ('secondary adjuvant therapy'), it is still recommended to initiate 
an endocrine treatment or to switch to another endocrine compound in endocrine-responsive disease. However, for chemotherapy and also for trastuzumab, evidence is lacking, therefore it cannot be generally recommended.

\section{Metastatic Disease}

The philosophy of the treatment of patients with metastatic breast cancer is still unchanged. Treatment modalities should be adapted to the patient's needs and guided by the situation of the disease. Particularly, the necessity of a rapid remission, the expected effects, and the potential toxicities must be balanced carefully. As a standard of care, type and extent of metastases have to be confirmed, and single sites should be defined as lead metastases prior to initiating therapy in order to monitor the therapy effect. Predictive markers such as steroid hormone receptor status, HER2 status, and menopausal status can help to rationally define the use of a distinct therapy. In endocrine responsive disease, hormone therapy is the standard first line treatment. Only if rapid remission seems to be required, or if the tumor seems not to be endocrine-responsive, chemotherapy should be administered primarily. Bisphosphonates are the standard of care in the case of bone metastases. In the case of single metastases, selective surgery or radiotherapy can be tried. Radiotherapy of affected skeletal sites should always be discussed for treating or preventing fractures and pain. Surgery and radiotherapy are standard measures in brain metastasis.

\section{Endocrine Therapy of metastatic disease}

In endocrine responsive metastatic disease, endocrine therapy is considered as the standard first step of treatment. Only in situation where a rapid remission is required, chemotherapy should be used. In premenopausal patients, ovarian suppression plus tamoxifen is the standard first line therapy. In postmenopausal patients, aromatase inhibitors (and in some cases also tamoxifen) should be used as first line drugs. In most cases, further endocrine therapy steps are feasible in second and third line situations, using endocrine compounds that were not used so far. In general, combination with chemotherapy is not indicated as the potential additional risk of side effects is not outweighed by any additional benefit; prolongation of progression-free or overall survival can usually not be expected. On the other hand, after induction of remission by chemotherapy, preservation of the remission should be tried by appropriate hormone therapy in patients with endocrine-responsive cancer. HER2-overexpressing tumors tend to be less responsive to endocrine therapies. The combination anastrozole plus trastuzumab has not demonstrated convincing results, such that this combination cannot be recommended as a standard treatment. Most patients with HER2-overexpressing tumors would require a primary trastuzumab chemotherapy combination, even with positive steroid hormone receptor status.

\section{Chemotherapy of metastatic disease}

With respect to chemotherapy, single agent therapies are preferred for exhibiting a better therapeutic index. The treatment should be continued as long as the therapeutic index is sustaining it. Anthracyclines, liposomal and PEG-liposomal anthracyclines, taxanes, and in some cases capecitabine are the most recommended compounds in first line treatment. Also vinorelbine may be a reasonable alternative. In the chapter 'Targeted Therapies', the standard indications and standard combinations for trastuzumab therapy in the treatment of metastatic breast cancer are extensively documented. Also, the potential use of new drugs like lapatinib (small molecule against HER1/HER2) or bevacizumab (monoclonal antibody against vascular endothelial growth factor (VEGF)) is analyzed.

\section{Conclusion}

These recommendations represent the current knowledge of diagnosis and therapy of breast cancer in an evidence-based manner, and may be helpful for clinical decision-making.

\section{References}

1 Jackisch C, Untch M, Chatsiproios D, Lamparter C, Overkamp F, Lichtenegger W, Ronsberg W, Thomssen C, von Minckwitz G: Breast cancer: analysis of treatment quality in Germany 2004: retrospective survey by Arbeitsgemeinschaft Gynakologische Onkologie (AGO). Zentralbl Gynakol 2006;128:352-61.

2 Thomssen C: Arbeitsgemeinschaft für Gynäkologische Onkologie - Kommission Mamma. Hinweise für die Überarbeitung der AGO-Leitlinien zum Mammakarzinom. SOP Leitlinie AGO Kommission Mamma, 2007.

- 3 Elsheikh TM, Silverman JF: Follow-up surgical ex cision is indicated when breast core needle biopsies show atypical lobular hyperplasia or lobular carcinoma in situ: a correlative study of 33 patients with review of the literature. Am J Surg Pathol 2005; 29:534-43.
4 Mahoney MC, Robinson-Smith TM, Shaughnessy EA: Lobular neoplasia at 11-gauge vacuum-assisted stereotactic biopsy: correlation with surgical excisional biopsy and mammographic follow-up. AJR Am J Roentgenol 2006;187:949-54.

$\checkmark 5$ EORTC Breast Cancer Cooperative Group; EORTC Radiotherapy Group, Bijker N, Meijnen P, Peterse JL, Bogaerts J, van Hoorebeeck I, Julien JP, Gennaro M, Rouanet P, Avril A, Fentiman IS, Bartelink H, Rutgers EJ: Breast-conserving treatment with or without radiotherapy in ductal carcinoma-in-situ: ten-year results of European Organisation for Research and Treatment of Cancer randomized phase III trial 10853 - a study by the EORTC Breast Cancer Cooperative Group and EORTC Radiotherapy Group. J Clin Oncol 2006; 24:3381-7.
6 Slamon D, Eiermann W, Robert N, Pienkowski T, Martin M, Pawlicki M, Chan A, Smylie M, Liu M, Falkson C, Pinter T, Fornander T, Shiftan T, Valero V, Mackey J, Tabah-Fisch I, Buyse M, Lindsay M, Riva A, Bee V, Pegram M, Press M, Crown J BCIRG 006: 2nd interim analysis phase III randomized trial comparing doxorubicin and cyclophosphamide followed by docetaxel (AC T) with doxorubicin and cyclophosphamide followed by docetaxel and trastuzumab (AC TH) with docetaxel, carboplatin and trastuzumab (TCH) in Her2neu positive early breast cancer patients. Breast Cancer Res Treat 2006;100(suppl 1):abstr 52.

7 Roggel F, Hocke S, Lindemann K, Sinz S, Welk A, Bosl M, Pabst M, Nusser N, Braun S, Schmitt M Harbeck N: Minimal residual disease in breast cancer and gynecological malignancies: phenotype and clinical relevance. Recent Results Cancer Res 2003;162:89-100. 
8 Fehm T, Braun S, Muller V, Janni W, Gebauer G, Marth C, Schindlbeck C, Wallwiener D, Borgen E, Naume B, Pantel K, Solomayer E: A concept for the standardized detection of disseminated tumor cells in bone marrow from patients with primary breast cancer and its clinical implementation. Cancer 2006;107:885-92.

9 Early Breast Cancer Trialists' Collaborative Group (EBCTCG): Effects of chemotherapy and hormonal therapy for early breast cancer on recurrence and 15-year survival: an overview of the randomised trials. Lancet 2005;365:1687-717.

10 Piccart-Gebhart MJ, Procter M, Leyland-Jones B, Goldhirsch A, Untch M, Smith I, Gianni L, Baselga J, Bell R, Jackisch C, Cameron D, Dowsett M, Barrios CH, Steger G, Huang CS, Andersson M, Inbar M, Lichinitser M, Lang I, Nitz U, Iwata H, Thomssen C, Lohrisch C, Suter TM, Ruschoff J, Suto T, Greatorex V, Ward C, Straehle C, McFadden E, Dolci MS, Gelber RD; Herceptin Adjuvant (HERA) Trial Study Team: Trastuzumab after adjuvant chemotherapy in HER2-positive breast cancer. N Engl J Med 2005;353:1659-72.

11 Baselga J, Perez EA, Pienkowski T, Bell R: Adjuvant trastuzumab: a milestone in the treatment of HER-2-positive early breast cancer. Oncologist 2006;11(suppl 1):4-12. Review.

12 Green MC, Buzdar AU, Smith T, Ibrahim NK, Valero V, Rosales MF, Cristofanilli M, Booser DJ, Pusztai L, Rivera E, Theriault RL, Carter C, Frye D, Hunt KK, Symmans WF, Strom EA, Sahin AA, Sikov W, Hortobagyi GN: Weekly paclitaxel improves pathologic complete remission in operable breast cancer when compared with paclitaxel once every 3 weeks. J Clin Oncol. 2005;23:5983-92. 